Transportation Research Forum

Deriving Rules for Forecasting Air Carrier Financial Stress and Insolvency: A Genetic Algorithm Approach

Author(s): Sergio Davalos, Richard D. Gritta, and Bahram Adrangi

Source: Journal of the Transportation Research Forum, Vol. 46, No. 2 (Summer 2007), pp. 63-81

Published by: Transportation Research Forum

Stable URL: http://www.trforum.org/journal

The Transportation Research Forum, founded in 1958, is an independent, nonprofit organization of transportation professionals who conduct, use, and benefit from research. Its purpose is to provide an impartial meeting ground for carriers, shippers, government officials, consultants, university researchers, suppliers, and others seeking exchange of information and ideas related to both passenger and freight transportation. More information on the Transportation Research Forum can be found on the Web at www.trforum.org. 


\title{
Deriving Rules for Forecasting Air Carrier Financial Stress and Insolvency: A Genetic Algorithm Approach
}

\author{
by Sergio Davalos, Richard D. Gritta, and Bahram Adrangi
}

\begin{abstract}
Statistical and artificial intelligence methods have successfully classified organizational solvency, but are limited in terms of generalization, knowledge on how a conclusion was reached, convergence to a local optima, or inconsistent results. Issues such as dimensionality reduction and feature selection can also affect a model's performance. This research explores the use of the genetic algorithm that has the advantages of the artificial neural network but without its limitations. The genetic algorithm model resulted in a set of easy to understand, if-then rules that were used to assess U.S. air carrier solvency with a $94 \%$ accuracy.
\end{abstract}

\section{INTRODUCTION}

A bankruptcy prediction model has a broad base of stakeholders: lenders, auditors, investors, consultants, the flying public, and government policy makers (Gritta et al. 2003; O'Leary 1998). Bankruptcy prediction models based on financial data have been studied since the late 1960s and continue to be used today (Shin and Lee 2002; Zhang et al. 1999). By 1996 there were at least 158 published articles concerning business failures (Dimitras et al. 1996). The primary approaches to predict failure are: 1) statistical models (primarily discriminant analysis (MDA)), conditional logit regression analysis, and probit models and 2) machine learning: artificial neural networks (ANN), and genetic algorithms (GA). Beaver's (1966) univariate analysis model was based on financial ratios to classify failed and non-failed firms. This led to the multivariate analyses conducted by Altman and others. These initial bankruptcy studies used statistical analysis techniques such as MDA (Altman 1968, and 1983; Altman et al. 1977), logit (Ohlson 1980), and probit (Zmijewski 1984). Beaver's and Altman's work set the foundation for decades of research. Altman derived a function, Z-score, from the financial ratios of 66 manufacturing firms using MDA which was based on Fisher's linear discriminant analysis (FLDA) method for maximizing between group differences and minimizing within group differences (Fisher 1936). Lev (1974), Deakin (1972), Ohlson (1980), Taffler and Houston (1980), Platt and Platt (1990), Gilbert, Menon, and Schwartz (1990), Koh and Killough (1990), and Zavgren (1983) continued the development of the multivariate statistical models. Their models differ with respect to assumptions on group distributions of data and the form of the discriminant function.

The major drawback of these methods is that real-world data does not often satisfy the assumptions of the MDA models (Bhattacharyya and Pendharkar 1998; Grover and Lavin 2001). Decision tree analysis was applied to address such statistical problems (Messier and Hansen 1988). In the early 1990s other approaches, ANN model being the most common, resulted in an increase in predictive accuracy (Hekanaho et al. 1998). In general, the classification accuracy of ANNs is at least comparable to logit and MDA models. Beginning in the mid 1990s, genetic algorithm (GA) computing models were applied to bankruptcy classification (Back et al. 1994; Sikora and Shaw 1994; Galvao et al. 2002; Sexton et al. 2003).

As the number of air carrier insolvencies has increased steadily in the years after deregulation of the industry, forecasting the financial stress and bankruptcy in the U.S. airline industry has become quite important over the past decade. Previous research studies by the authors (Chow et al. 1991; Davalos et al. 2002; Goodfriend et al. 2005; Gritta et al. 2003) used logit, MDA, and ANNs. While 
these methods have successfully classified airlines in terms of solvency or insolvency based on financial data, they are limited in generalizability, require linearly separable variables, provide no knowledge of how a conclusion is reached, lack a consistent approach for applying the ANN, and can get stuck in a local optimal. The GA method can deal with linearly inseparable variables and incomplete, noisy data, produces consistent results, and resolves the problem of falling into a local optimum in searching the problems space.

Based on the previous work conducted by researchers in bankruptcy and insolvency and in the application of machine learning approaches to discrimination and classification tasks, we wanted to answer the following questions:

- How can a GA be used to classify airlines in terms of solvency and insolvency based on air carrier quarterly financial data?

- What form does a GA model need to take to be transparent, adaptive, and understandable - comprehensible?

- How does the GA's performance compare to other bankruptcy forecasting models?

- Are there unique aspects to using GA to solve bankruptcy problems?

The paper discusses the development of the GA model first presented by Davalos et al. (2006) for predicting air carrier solvency on a sample of U.S. airlines using air carrier financial data. Such a study is of interest to a large numbers of stakeholders. Although there has been ongoing research on bankruptcy prediction for almost 30 years, an adequate theory of how and why corporations fail has not yet been developed (Wilcox 1973; Varetto 1998; Lensberg et al. 2004 ). This paper contributes to the development of such a theory. The rest of the paper is organized as follows: the next section discusses previous related work, and the following sections introduce the research framework for the study and present the results and the implications and limitations of the research. Conclusions are reserved to the final section.

\section{FINANCIAL SOLVENCY}

Three key issues need to be addressed for developing a financial solvency model: the characteristics of the model, dimensionality reduction, ${ }^{1}$ and feature selection ${ }^{2}$. The primary models used in bankruptcy research are based on classification (Lensberg et al. 2004) and on statistical inference and machine learning methods (Zhang and Zhou 2004). However, models are not applicable in all cases because each model has different data and information requirements with differing degrees of transparency and comprehension. For instance, Hopwood et al. (1994) suggested that different bankruptcy models are applicable to stressed and non-stressed firms and included a non-financial feature - the auditor's decision. Standard statistical models work best when statistical assumptions for the predictor variables are met: 1) the values are normally distributed, 2) the variables are linearly separable and are independent from other predictor variables, 3) that there is a function that relates the predictor variables to the dependent variable, and 4) that the variance-covariance matrix is homogeneous (Fisher 1936; Ohlson 1980; Klecka 1980; Zhang et al. 1999). These models have a fair degree of accuracy and may still be robust even when these conditions are not met (Klecka 1980; Markham and Rasgdale 1995; Ohlson 1980; Back et al. 1997; Grover and Lavin 2001). Dimensionality reduction is necessary when there is a large number of variables (dimensions) in the data set, because it is likely that the distribution of the data points will be spread too thin to meet desired levels of significance and accuracy (Zmijewski 1984). Feature selection reduces the number of dimensions (variables) and the amount of data processing by selecting the features (variables) used in a model (Ohlson 1980).

\section{Prediction Models}

Statistical prediction methods include univariate and multivariate analysis. Primary multivariate methods include cluster analysis, factor analysis, MDA, multidimensional scaling, logit, regression, 
probit analysis, Fischer's LDA, Altman's Z Score, and logit-probit (Zhang et al. 1999; Zhang and Zhou 2004). Hamer (1983) reviewed MDA, probit, and logit studies and found that relatively little differences in the predictive accuracy between the models. The need to improve general, prediction statistical model accuracy led to the use of machine learning classification models.

Machine learning models, a special branch of artificial intelligence, include: rule induction also knows as concept learning, ANN, and GA (Varetto 1998; Zhang and Zhou 2004). ANNs are computing models based on neural structure of the brain and learn through experience (data) and can adapt as the data changes. Rule induction methods develop a symbolic classification model - a set of if-then rules that can be applied to the data set. Common rule induction methods are covering approach, ID3, recursive partitioning, and C3 (Michalski 1983). ANNs are a commonly used technique for financial applications (Zhang and Zhou 2004). The GA model developed by Holland (1997) had been used successfully in classification. GAs are stochastic, parallel, global search techniques that can search large, complicated data spaces (Goldberg 1989). Financial applications of GA include trading system (Colin 1994; Deboeck 1994), stock and portfolio selection (Mahfoud and Mani 1995; Rutan 1993).

Concept learning or rule induction has been applied to the task of insolvency classification (Varetto 1998). Concept learning corresponds to developing rules for classification. The rules are then used to classify new instances in the problem space. The rule induction method has the advantage that it generates rules that are intelligible to humans (Back et al. 1997). The justification for this approach is that it is easier for experts to produce examples of sound and unsound firms than to formulate a theory based on the financial signals of companies prior to insolvency (Varetto 1998). The most common form of this approach is decision trees analysis based on financial variables or ratios. Most rule induction methods involve sequential development of rules where rules are learned one at a time and the more general rules are first discovered and then increasingly more specific rules are learned. This can be problematic when the sequence can affect the outcome and it is then necessary to try every possible combination of sequences. This is not feasible for combinatorially large problems.

The first ANN bankruptcy prediction studies were those of Odom and Sharda (1990) and Bell et al. (1990). Subsequent researchers include: Hansen and Messier (1991), Chung and Tam (1992), Liang et al. (1992), Tam and Kiang (1992), Salchenberger et al. (1992), Coats and Fant (1993), Fanning and Cogger (1994), Brockett et al. (1994), Boritz et al. (1995), and Etheridge and Siriam (1996 and 1997). Lacher et al. (1995), Sharda and Wilson (1996), Tam and Kiang (1992), and Wilson and Sharda (1994) reported significantly better accuracy with ANNs than with traditional statistical methods. In theory, ANN is a universal function approximation method that can perform as well as any other function-based method because it can approximate any measurable function to any degree of accuracy (Markham and Ragsdale 1995; Sharda 1994). ANNs have been shown to have accuracy equal to that of MDA without the restrictions of MDA criteria (Hornick et al. 1989). ANNs have been applied to the discrimination problem in numerous studies (Archer and Wang 1993; Patuwo et al. 1993; Sharda 1994; Tam 1991; Tam and Kiang 1992; Yoon et al. 1993).

Unlike MDA and logit analyses, ANN's impose less restrictive data requirements and are especially useful in recognizing and learning complex data relationships and, unlike rule induction methods, can examine rule conditions in parallel. The use of ANN has had mixed and inconsistent results where in some cases ANN outperform statistical methods and in others are outperformed (Markham and Ragsdale 1995). This can be attributed to an inadequate theory on the proper ANN architecture in terms of layers and nodes, an inadequate learning algorithm, no relationship between the dependent and independent variables, the size of the training data and test sets, the type and distribution of data, the size of the search space, convergence to a local optimum, the nature of the problem, and the proportion of bankrupt to non-bankrupt classified firms (Markham and Ragsdale 1995; Anandarajan et al. 2001). In addition, ANN's are "black boxes" in that the individual role of each of variables cannot be easily determined. An additional problem with ANNs is over fitting. Over fitting occurs when the resulting ANN has converged to fitted coefficients that are not 
generalizeable (Back et al. 1997). This easily occurs with small data sets and with a large number of model coefficients.

Approaches to improve ANN performance include combining ANN with statistical methods (Markham and Ragsdale 1995; Hekanaho 1997). Hekanaho et al. (1998) examined three methods for bankruptcy prediction: logit analysis, ANN, and rule induction and found that, in general, ANN and rule induction had a higher predictive accuracy than logit analysis when the sample size is large. Henkanaho (1997) and Sexton et al. (2003) combined neural networks with a genetic algorithm (GA) where the GA's role is as a feature selection procedure for the neural network. The GA model performed better than ANN, MDA, and logit, and the genetic algorithm rules can be learned in parallel (Back et al. 1997). Sikora and Shaw (1994) developed a hybrid ANN-GA model that derived if-then rules for bankruptcy prediction. The model used integer values for the thresholds and the focus of the GA was to provide feature selection support for a neural network model. Sexton et al. (2003) developed a similar GA model that provided the front-end (the feature selection) for a neural network model. Our work derives from this basis and includes factors not directly addressed: dimensionality reduction and feature selection.

\section{Dimensionality (Variable) Reduction}

Dimensionality reduction can improve the effectiveness of a model because less data is required for the desired level of accuracy, the complexity of the model is less, and less data processing is required. One approach is to use ratios that combine several variables. Another approach is to develop a function such as LDA or MDA that incorporates variables or ratios. Feature selection is another approach. However, there is no established method for dimensionality reduction and finding the optimal set is complex because the number of combinations of variables makes the determination of an optimal solution computationally unfeasible (Varetto 1998).

\section{Financial Ratios}

Financial ratios provide variable dimensionality reduction and are useful for conducting economicfinancial analysis of a firm by measuring profitability, liquidity, and solvency (Varetto 1998; Lacher et al. 1995; Altman 2000). Initial use of ratios was in univariate models but multivariate models proved more predictive (Deakin 1972; Lacher et al. 1995; Altman 1968 and 2000). However, the particular set of ratios to use has not been determined. Beaver (1966) found that the financial ratios of failing firms were different than those of healthy firms. Altman's 1968 MDA model for financial distress analysis identified the relative weights of individual ratios when used in combination (Lacher et al. 1995; Altman 2000) and increased the value of financial ratios for financial analysis (Altman 2000). Altman (1968) identified 22 variables with potential for bankruptcy prediction and identified a profile of five ratios that were combined to provide a multivariate model.

In a study of ratios proven to have predictive value, Courtis (1978) found 79 financial ratios of value and classified them into three categories: profitability, solvency, and managerial performance. Ohlson (1980) examined the use of financial ratios for bankruptcy prediction and based on frequency of occurrence in the literature identified four basic factors that were statistically significant in determining the probability of bankruptcy: 1) firm size, 2) measure of financial structure, 3) measure(s) of performance, and 4) measure(s) of current liquidity. However, he was not able to state in general which ratios are best, when, and why. He suggested that a more in-depth study would involve trying out the different combinations of variables and adding or subtracting variables used in the different models. Subsequent models have focused on determining which ratios to use (Back et al. 1996). Back et al. (1996a) found 31 ratios used in previous bankruptcy studies. Hekanaho et al. (1998) used 33 ratios derived from previous bankruptcy studies in a model that tried combinations of ratios until the optimal set is found. Grover and Lavin (2001) derived 24 ratios based on six categories: liquidity, profitability, leverage, solvency, activity, and miscellaneous. 


\section{Feature Selection}

Feature selection involves identifying the optimal set of features to use in the model and has the benefit of reducing model complexity (Hekanaho 1997). There is no theoretical basis for selecting ratios (Altman 2000; Back et al. 1996a). As a consequence, different ratios may be relevant to different models. Most modeling techniques require the researcher to select the ratios to use which is problematic because there are a large number of candidate ratios. One common method is the stepwise refinement method and can improve the performance of MDA and logit (Hekanaho et al. 1998) but it may not identify the optimal combination of features (variables) due to the number of possible combinations of variables and values. The GA has the ability to find an optimal or near-optimal combination of features with a high level of accuracy in a reasonable amount of time in a parallel manner ${ }^{3}$. Hekanaho (1997) used the GA to derive a set of if-then rules for classification. However, it was not applied in bankruptcy prediction. Hekanaho et al. (1998) applied the GA method to select the variables for an ANN to identify features that were the best predictors. Galvao et al. (2002) examined the use of a GA for feature selection for the variables of a discriminant function.

\section{Genetic Algorithms and Classification}

Use of the GA for bankruptcy classification can involve the generation of a linear discriminant-type of function, genetic linear function (GLF), or the generation of if-then rules (Varetto 1998). The GLF calculates a score that is then used for classification and can assume the form

$$
\text { Score }=\mathrm{a}_{0}+\mathrm{a}_{1} * \mathrm{R}_{\mathrm{h} 1}+\mathrm{a}_{2} * \mathrm{R}_{\mathrm{j} 2}+\ldots+\mathrm{a}_{\mathrm{n}} * \mathrm{R}_{\mathrm{mn}}
$$

$a_{0}$ is a constant, $a_{j}$ is the $j$ th coefficient, $R_{k j}$ is the kth ratio in the jth position. The GA derives the values for the constants, coefficients, and particular ratios that provides the best score for bankruptcy classification. Varetto (1998) used the above scoring method and generated structured rules as follows:

$$
\begin{aligned}
& \text { IF } \mathrm{R}_{\mathrm{h} 1}>\mathrm{X}_{1} \text { THEN Score }=\text { Score } \pm \mathrm{V}_{1} \\
& \text { IF } \mathrm{R}_{\mathrm{j} 2}>\mathrm{X}_{2} \text { THEN Score }=\text { Score } \pm \mathrm{V}_{2} \\
& \text { IF } \mathrm{R}_{\mathrm{mn}}>\mathrm{X}_{\mathrm{n}} \text { THEN Score }=\text { Score } \pm \mathrm{V}_{\mathrm{n}} \\
& \text { IF Score }>=0 \text { THEN Firm is Solvent } \\
& \text { IF Score }<0 \text { THEN Firm is Insolvent }
\end{aligned}
$$

Each $\mathrm{V}_{\mathrm{i}}$ is a value for reducing or increasing the score when a rule is true. Each $\mathrm{X}_{\mathrm{i}}$ is a value that is conditionally tested with the designated ratio $\left(\mathrm{R}_{\mathrm{mi}}\right)$. The GA derives the ratios $\left(\mathrm{R}_{\mathrm{mi}}\right)$ to be used, the type of conditional test $(<,>,<=)$, the $\mathrm{X}_{\mathrm{i}}$ thresholds, and the value for $\left(\mathrm{V}_{\mathrm{i}}\right)$ increasing or decreasing the score. An example rule is:

If CA/TA $>4.7$ THEN Score $=$ Score +2.4 .

Fidelis et al. (2000) used a GA to generate a set of rules where each rule is a conjunction of conditions of the following form:

RULEn: $\quad$ IF $\mathrm{R}_{\mathrm{h} 1}>\mathrm{X}_{1}$ AND $\mathrm{R}_{\mathrm{j} 2}<=\mathrm{X}_{2} \ldots$ AND $\mathrm{R}_{\mathrm{mn}}>\mathrm{X}_{\mathrm{n}}$ THEN Insolvent

Note: the operators depicted are used for illustrative purposes.

Each rule is a disjunctive ${ }^{4}$ part of a concept $-\mathrm{C}$ - where

$$
\mathrm{C}=\text { Rule1 V Rule2 V ...V Rulen }
$$

In this case, the concept (bankruptcy) is determined by a set of rules. The GA determines which ratios to use, the type of condition for each disjunctive, and the thresholds that best classify the data. ${ }^{4}$ The GA generates rules until either an accuracy threshold is reached or a certain number of iterations is reached with no improvement. Fidelis et al. (2000) did not examine bankruptcy prediction and used integer values for the threshold. Shin and Han (2004) used a similar approach and used stepwise refinement for variable selection. 
Forecasting Air Carrier Financial Stress

\section{RESEARCH APPROACH}

\section{Requirements for Classification}

The selection of a bankruptcy prediction model must address several issues: dimensionality reduction, feature selection, and type and transparency of the model. In this study we present an alternative model for the purpose of increasing the level of predictive accuracy, identifying the key ratios that need to be included, and deriving a high degree of explanatory power by providing insight on comprehensible conceptual patterns or structures; if-then rules are based on ratios.

\section{Genetic Algorithm}

The three main aspects of the genetic algorithm are coding of rules, genetic operators on rules, and fitness function. A GA starts with a set of candidate solutions, called chromosomes, for a problem. Each chromosome is a numeric vector. The individual components of a vector are known as a genes. Each chromosome represents a combination of values that are a solution for a particular problem. Candidate solutions (chromosomes) are evaluated by using a fitness function that determines its performance. A fitness function measures the current solution in terms of the desired outcome. Based on the fitness function measurements, the best performing solutions are used to improve the solutions.

Solutions need to be coded into a computational form. Each rule is coded as a chromosome that is divided into $n$ genes, where each gene corresponds to a condition involving one attribute, and $n$ is the number of predicting attributes used. Genes are positional where the first gene represents the first attribute, the second gene represents the second attribute, and so on. Each i-th gene, $i=1 \ldots n$, has three fields: variable (Var), logical operator (Op) and value (X). A chromosome of the following form was used to encode the rules:

(1) (Var1, Op1, X1, Var2, Op2, X2, ... Varn, Opn, Xn).

A gene then corresponds to one condition in the IF part of a rule, and the entire chromosome (individual) corresponds to the entire IF part of the rule. The THEN part is not coded. Based on the GA chromosome above, rules take on the following form:

\section{(2) If Var1 > X1, And Var2 < X2, ... And VarN5 > X5}

Then Solvency (or insolvency)

(Specific operators were used to better illustrate the format)

Once the fitness of candidate chromosomes has been determined, chromosomes are selected for the next generation of solutions based on the fitness function. Chromosomes with a higher fitness have a greater likelihood of being included in the next generation. Additional chromosomes are added to the remaining candidate solutions. These additional chromosomes are generated by reproduction functions. The basic GA reproduction operators are based on crossover, and mutation. In crossover, part of one chromosome is combined with part of another chromosome. The objective is that the combination will yield an even better chromosome. This operation takes two chromosomes, the parents, that are split at a crossover point and produces two new ones, the offspring. The mating occurs at crossover points (see Figure 1) to produce a new chromosome. Two new members (chromosomes) are generated. The new chromosomes contain values from the first parent's variables combined with the values from the second. In mutation (Table 1), genes are randomly selected and take on a random value, and as a result, new chromosomes are generated. With mutation, new genetic material is introduced or re-introduces material that had been lost (Sikora and Shaw 1994). 
The resulting set of chromosomes is a new candidate population of solutions. A more thorough description of genetic algorithms is provided in Goldberg (1989).

Table 1: Example of the Genetic Operators: Crossover and Mutation

\begin{tabular}{|c|c|c|c|c|c|}
\hline \multicolumn{6}{|c|}{ INITIAL POPULATION } \\
\hline Chromosome & Varl & $\mathrm{V}$ ar2 & V ar3 & V ar4 & Fitness \\
\hline 1 & 8.83 & 25.12 & 29.59 & 5.34 & 331.15 \\
\hline 2 & 7.12 & 21.05 & 33.15 & 4.32 & 297.33 \\
\hline 3 & 6.92 & 28.37 & 31.92 & 5.79 & 453.87 \\
\hline \multirow[t]{2}{*}{4} & 8.22 & 25.89 & 30.85 & 5.97 & 409.06 \\
\hline & \multicolumn{5}{|c|}{ CROSSOVER AND MUTATION } \\
\hline 1 & 8.83 & 25.12 & 33.15 & 4.32 & 301.55 \\
\hline 2 & 7.12 & 21.05 & 29.59 & 5.34 & 397.35 \\
\hline 3 & 6.92 & 28.37 & 33.92 & 5.79 & 253.29 \\
\hline \multirow[t]{2}{*}{4} & 8.22 & 20.89 & 3192 & 5.07 & 478.56 \\
\hline & \multicolumn{4}{|c|}{ NEW POPULATION } & M utatio \\
\hline 1 & 8.83 & 25.12 & 29.59 & 5.34 & 331.15 \\
\hline 2 & 7.12 & 21.05 & 33.15 & 4.32 & 297.33 \\
\hline 3 & 6.92 & 28.37 & 31.92 & 5.79 & 453.87 \\
\hline 4 & 8.22 & 25.89 & 30.85 & 5.97 & 409.06 \\
\hline 5 & 8.83 & 25.12 & 33.15 & 4.32 & 301.55 \\
\hline 6 & 7.12 & 21.05 & 29.59 & 5.34 & 397.35 \\
\hline 7 & 6.92 & 28.37 & 33.92 & 5.79 & 253.29 \\
\hline 8 & 8.22 & 20.89 & 31.92 & 5.07 & 478.56 \\
\hline
\end{tabular}

In summary, the steps of the genetic algorithm are as follows:

1. A population of candidate solutions is randomly generated.

2. Members of this population are then evaluated for fitness based on a fitness function to determine how well the candidate solutions perform.

3. In the next step, members are removed from the population based on an algorithm that favors removing the least-fit members. The number removed depends on how many are in the population, but this number must be consistent.

4. New members of the population are generated on the basis of crossover and mutation.

5. The new population then goes through steps 2-4 until a predetermined level of fitness is reached or enough iterations have been conducted without any improvement.

\section{Fitness Function}

The fitness function was based on the following four different types of results that can occur for a prediction:

- true positive (tp) - the rule predicts that the firm is financially solvent and it is.

- false positive (f) - the rule predicts that the firm is financially solvent and it is not.

- true negative (tn) - the rule predicts that the firm is financially insolvent and it is.

- false negative (fn) - the rule predicts that that the firm is financially insolvent and it is not. 
Forecasting Air Carrier Financial Stress

The fitness function combines two indicators, namely the sensitivity (Se) and the specificity $(S p)$, defined as follows:

(3)

$$
S e=t p /(t p+f n)
$$

$$
S p=t n /(t n+f p)
$$

Finally, the fitness function used by the system is defined as the product of these two indicators, i.e.:

$$
\text { fitness }=S e * S p
$$

Therefore, the goal is to maximize both the $\boldsymbol{S} \boldsymbol{e}$ and the $\boldsymbol{S p}$ at the same time, and the product shown in equation (5) provides a good gradient for the function.

\section{GA Data}

For this research, an initial set of 20 financial variables was selected (Appendix Two) from 19 air carrier (Appendix One) quarterly financial statements (U.S. Department of Transportation, Air Carrier Financial Statistics Quarterly, various issues) for the period from 1986-1996. For each carrier, several years of data were included and treated as separate data samples. Air carriers were classified as insolvent up to three years prior to bankruptcy and included the bankruptcy year. They were classified as solvent otherwise. This categorizing follows the Altman (1968) approach. Nine ratios were used based on four types of financial ratios:

- four liquidity measures - cash flow to total assets (CASH/TA); current liabilities to total assets (CLIAB/TA); current assets to operating revenue (CA/REV); current assets to total assets (CA/TA)

- $\quad$ three profitability measures - net income to equity (NETINC/EQUITY); retained earnings to total assets (REARN/TA); profit to operating expenses (PROFIT/OE)

- an efficiency ratio-operating expenses to revenue (OE/REV)

- a financial leverage measure-total liabilities to total assets (TLIAB/TA).

The data consisted of an equal number of matched solvent and insolvent firms. The firms were matched on the basis of revenue. The data was normalized ${ }^{5}$ to accommodate the neural network and was also used for the genetic algorithm. Because the data was in Excel format, the only additional data preparation required was calculation of the ratios.

\section{Model Validation}

Validation of classification models is accomplished by randomly dividing the entire available data set into a training set and a test (or hold out sample) set. The training set serves to condition the model. After the model has been conditioned with a training set, the test set is then used to evaluate the model. While this technique is standard, the method for dividing the data set is not (Zhang et al. 1999). A common practice is to split the data set randomly 50-50 into a test set and a training set. However, this can result in inadequate sample sets and can introduce bias in model selection and evaluation. This can occur if the test set has different characteristics from the training set (Zhang et al. 1999). As a result the estimated classification model may reflect the training set and not the true classification model. This is likely to occur with small-size samples.

In addition, the percentage of each group (failed/non-failed) in the sample set needs to be carefully considered. The ratio of failed to non-failed can have a substantial impact on the performance of the model (O'Leary 1998). Setting the training set and test set group percentages to reflect that of the target population can result in a model that is not predictive at all when the percentage of one group is low. For instance, if the percentage of group B is $10 \%$ of the population and the training and test sample sets have the same percentages, a classifier that always predicts group A ( $90 \%$ of the 
population) will be accurate $90 \%$ of the time. Boritz et al. (1995), Wilson and Sharda (1994) and Feroz and Kwon (1996) examined different proportions and determined that $50 \%$ provided the best results or results that were as good as a model with percentages that match the target population.

The sample size can also affect the performance of a model. Small sample sizes can result when the data set is made up of matched pairs (for the two group classification problem) and there is a much smaller percentage of one type in the original population. Henkanaho et al. (1998) and Back et al. (1997) examined the effect of sample size on the different failure prediction methods and found that for a larger sample size (400 vs. 200 and 100), machine learning methods (ANN and GA) performed better and there was no best performer for the smaller sample sizes.

When the sample size is small, cross-validation is a useful method. Cross-validation is a commonly used random sub-sampling technique (Tan et al. 2006) and has been used successfully to evaluate the predictive accuracy of neural networks (Zhang et al. 1999). Cross-validation involves re-sampling of the sample data with multiple random training and test sub-samples. One such cross-validation method is the $\mathrm{n}$-fold (leave k out) method where the $\mathrm{n}$ (usually $10 \%$ of the total) data records are reserved from the sample set as the test set. The remaining data records are used as the training set This is repeated enough times so that every data record is used at least once in the training set and the test set The results are averaged to reflect the model's performance. The advantage is that the data is used as much as possible. Sikora and Shaw (1994) point out that the leave-k out method tends toward an unbiased estimator. When $\mathrm{k}$ is 1 , all the observations are used for testing and training.

An initial training set of $50 \%$ was used to train the GA and a test set (the remaining $50 \%$ ) was used to evaluate the outcome. Several iterations were conducted to examine variations in performance. The average prediction accuracy was $91 \%$. After the initial runs with both a 50-50 data set split and the leave-k out method, the model was run based on a leave-k out method with $\mathrm{k}$ set to 1 . Two different fitness functions were used in separate runs. One was based on minimizing the number of errors. It was simply the sum of incorrect predictions. The second fitness function was based on equation 5. Both fitness functions derived the same sets of rules with the same data set However, the second fitness function took twice as long in processing. The average processing time using fitness function one was 22 minutes, while fitness function two took 44 minutes (1.33 Mhz Processor). The overall process time for all the data sets (52) was 19 hours for fitness function one and 38 for fitness function two. This time can be greatly reduced by using a faster processor. Trial runs with a $2.8 \mathrm{MHZ}$ processor reduced the time to five minutes for fitness function one.

\section{Setup}

The genetic algorithm used was a commercial one: Evolver by Palisades Systems. It is run as an Excel add-in, and on Windows XP/Professional. The GA was trained using the leave-k out method with $\mathrm{k}$ set to 1 . This maximized the use of the data set. For each run, one data element was removed and used as the test case. The rest were then used as the training set. This was repeated for each data element. After each training run, the model was tested. The results for each test provided a measure of the overall accuracy by dividing the number of correct predictions by the total. These were then averaged to get the overall accuracy.

\section{RESULTS}

A two-sample, multivariate T-test of the solvent and insolvent air carriers was conducted and the value was 0 indicating that there is a significant difference between the two groups. This is illustrated in Figure 1 which depicts the means of the ratios for nine solvent and the insolvent airlines. The REARN/TA stands out the most. 
Figure 1: Mean Ratios for the Solvent and Insolvent Carriers

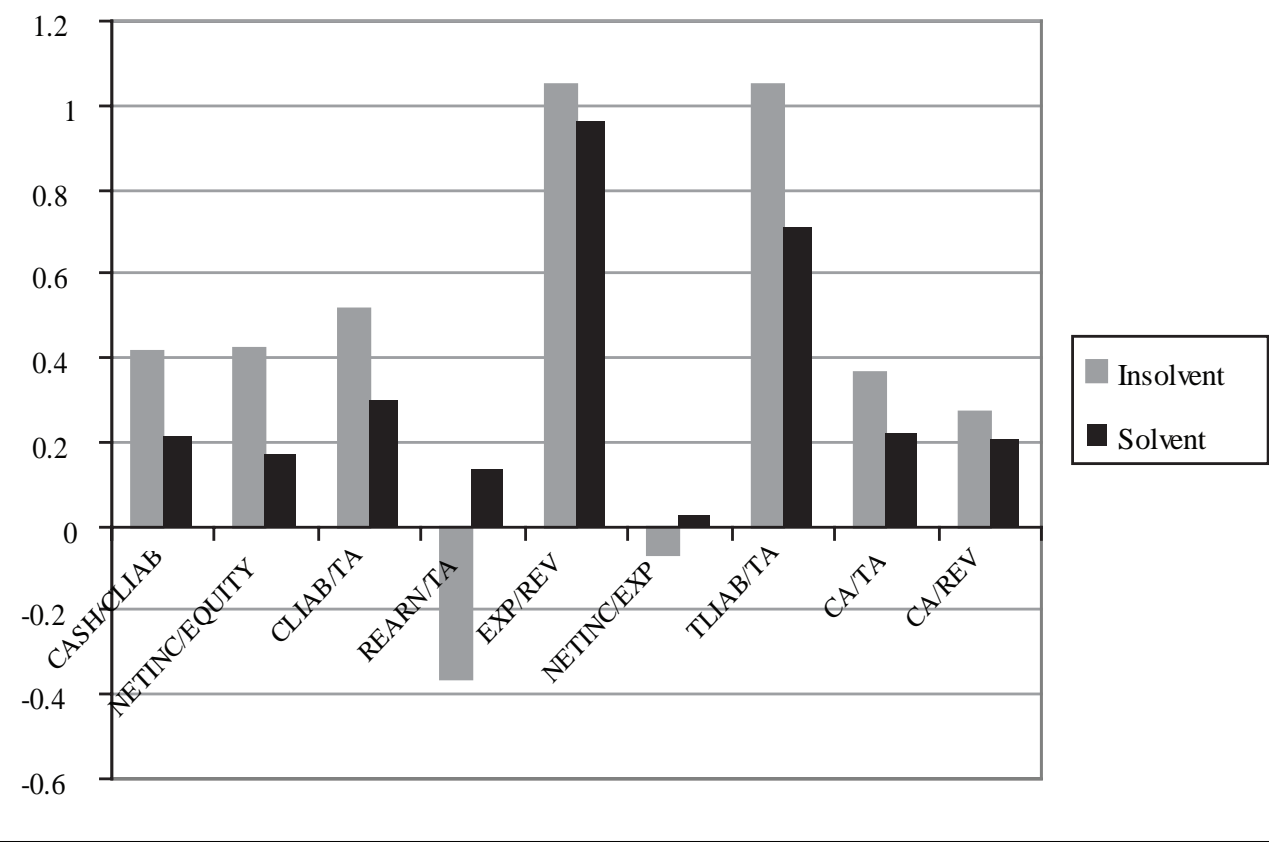

Table 2 depicts the results of a run with $94 \%$ accuracy. The ratio row references the ratio used. The operators are coded as either 1 or 2 with a 1 for "<" and a 2 for " $>=$ " and the cutoff row indicates the threshold for each condition of the rule.

Table 2: Example of Rule Generated by GA

\begin{tabular}{|l|c|c|c|c|c|c|}
\hline Condition \# & 1 & 2 & 3 & 4 & 5 & Value Range \\
\hline Ratio & 8 & 8 & 9 & 5 & 7 & $1-9$ [INT] \\
\hline Operator & 1 & 1 & 1 & 1 & 1 & $1-2$ [INT] \\
\hline Cutoff & 0.322 & 0.189 & 0.239 & 0.996 & 0.603 & $0-1$ \\
\hline
\end{tabular}

In the example, there are five conditions for one rule:

Rule 1: If CA/TA $<0.322$ AND CA/TA $<0.189$ AND CA/REV $<0.239$ AND EXP/SALES $<$ 0.996 AND TLIAB/TA $<0.603$ THEN INSOLVENT

In this model, for an airline to be predicted as financially insolvent all five conditions have to be true.

Tables 3 and 4 present the combined results of the genetic algorithm runs. There were no type I errors in any of the tests. There were only three type II errors. There were 52 tests altogether. The overall performance accuracy was $94 \%$.

Table 3: Actual vs. Predicted Results

\begin{tabular}{|l|c|c|c|}
\hline Actual & $\begin{array}{c}\text { Predicted } \\
\text { Solvent }\end{array}$ & $\begin{array}{c}\text { Predicted } \\
\text { Insolvent }\end{array}$ & Total \\
\hline Solvent & 23 & 3 & 26 \\
\hline Insolvent & 0 & 26 & 26 \\
\hline Total & 23 & 29 & 52 \\
\hline
\end{tabular}


Table 4: Correct with Type I and II Errors

\begin{tabular}{|l|r|}
\hline Solvent Correct & $88 \%$ \\
\hline Type I Error & $0 \%$ \\
\hline Type II Error & $12 \%$ \\
\hline Insolvent Correct & $100 \%$ \\
\hline Total Correct & $94 \%$ \\
\hline
\end{tabular}

Table 5 compares the results from the Altman Z-score model used by Gritta et al. (2003) for assessing air carrier fitness for the years 1986-1996 and with the neural network model used by Davalos et al. (2002).

Table 5: Comparison of Z-Score, ANN, GA Modeled on Air Carrier Data Set

\begin{tabular}{|l|c|c|c|c|}
\hline Model & Correct & Type 1 & Type 2 & Unclassified \\
\hline Z-Score & $4 \%$ & $6 \%$ & $19 \%$ & $71 \%$ \\
\hline Neural Network & $92 \%$ & $4 \%$ & $4 \%$ & $0 \%$ \\
\hline Genetic Algorithm & $94 \%$ & $0 \%$ & $6 \%$ & $0 \%$ \\
\hline
\end{tabular}

\section{DISCUSSION AND FUTURE RESEARCH}

All the rules generated were then tested against the entire data set and there was no loss in accuracy. One interesting result was that different ratios were used in different rules. Figure 2 depicts the frequency of occurrence of each ratio in all the generated rules. Ratio 4 - retained earnings to total assets - was the most common, occurring in 41 out of 52 rules. This indicates that ratio 4 was important in the GA predictions.

Figure 2. Frequency of Occurrence of Financial Ratios in GA Derived Rules

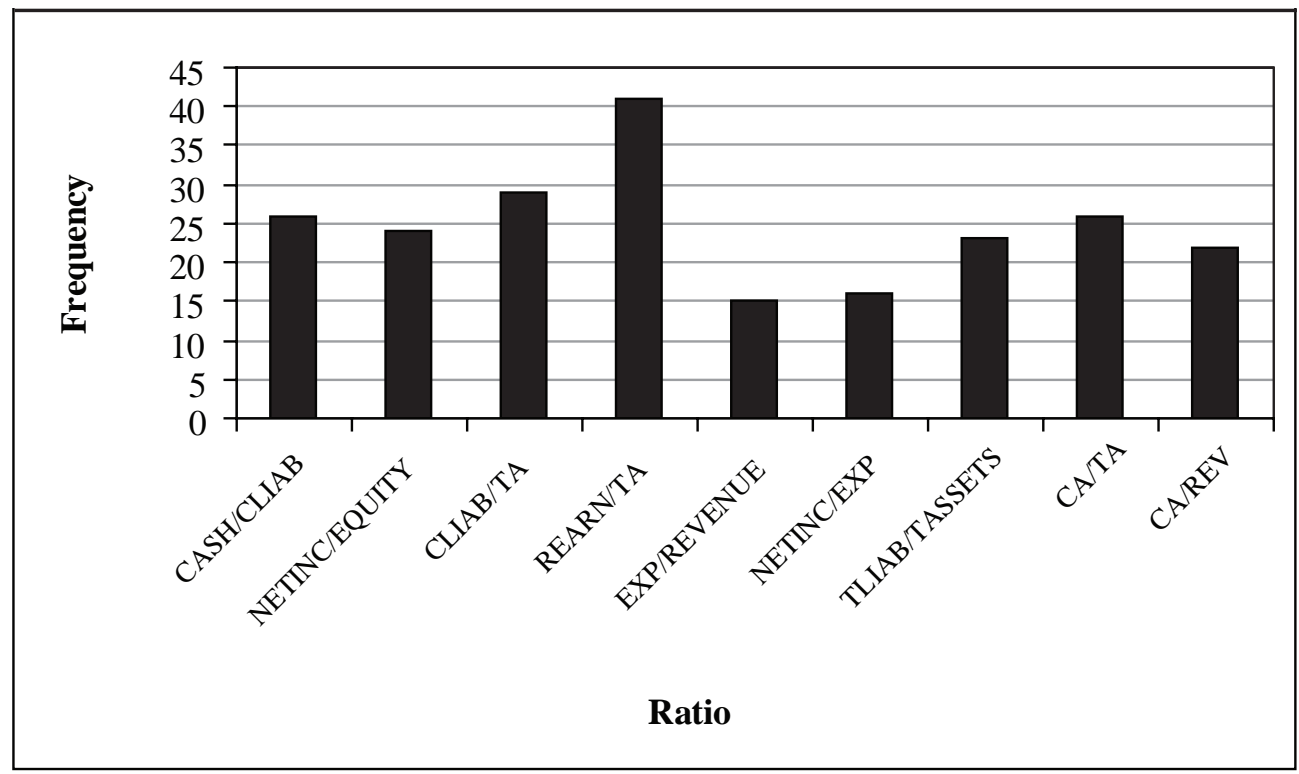

* See Appendix Two for definitions of variables to compute ratios. 
Forecasting Air Carrier Financial Stress

The GA model was selected for its ability to effectively address the issues of dimensionality reduction, feature selection, normality of the data, and transparency of the model. The GA method reduced dimensionality by focusing attention on the variables that contribute to rules with an increase in prediction performance. It also addressed feature selection by examining in parallel different combinations of features, operators, and values. Since a GA model does not have the data limitations and conditions of the statistical methods, a GA model can thus be used with a wider range of data distributions. Rules derived based on the GA, are more comprehensible and understandable in human terms. The fact that the GA had an accuracy of $94 \%$ is an added bonus. The results of this work can contribute toward a knowledge base for developing a theory of bankruptcy.

The data set used was based on a 1986 to 1996 time period. Future research will examine the performance of the GA for an out-of-period sample (1997 to 2007). This will identify two things: time-based factors that affect the model's performance and common factors. This research was based on frequently used financial ratios. Future research will increase the number of ratios used, examine the use of variables instead of ratios, and derive interval based rules - variable values are between two values. To further understand the nature of the airline industry, the GA method will be applied to a heterogeneous (industry) population. The derived rules from these other industries will then be compared against those generated from the airline industry. Finally, one of the advantages of using an approach such as the GA is that schemas for rules can be developed as the basis for the development of other rules and rules with more complex structures. This will aid in exploring rules that provide a better picture of solvency.

\section{CONCLUSION}

Chow et al. (1991) determined that the Altman Z-score models were limited for classifying air carrier insolvency. They developed a model, Airscore, with better accuracy. Subsequent research (Davalos et al. 2002; Gritta et al. 2003) focused on improving the level of accuracy. A limitation in developing a solvency model for air carriers is the size of the data set. There are not many air carriers so the data set is small. In addition, the airline industry financial structure is different from other industries (Chow et al. 1991). This requires a model that can meet those conditions. The genetic algorithm developed in this research addressed those conditions. Because the genetic algorithm is adaptive it can be readily adapted to changing conditions.

In this research we developed a GA-based model for solvency classification to address the limitations of previous models and provides concept learning (rule development) results. Because a theoretical basis for the selection of ratios in bankruptcy studies is yet to be developed, the ratios selected for this study were based on those often cited and most representative. The study used air carrier financial data on 20 variables from balance sheets and income statements, and ratios were calculated from those variables. The resulting GA model has an average $94 \%$ success rate in forecasting insolvency.

Future research will be aimed at increasing the reliability of the GA to predict insolvency. More variables will be added to the equation. The sample size used to specify the algorithm will also be increased. Further research can be focused on a broader set of ratios. In addition, expert review of the resulting rules can be used to further the development and identification of the key ratios. The rules that resulted from each training run were not the same in all cases. However, there were ratios that consistently emerged in the each rule set. This paper has introduced a newer technique useful in forecasting air carrier financial stress and insolvency-the genetic algorithm. GA's have advantages over statistical models, such as logit and MDA, and artificial neural networks. While retaining the ability of the ANN method to deal with linearly inseparable variables and incomplete, noisy data, the GA resolves the problem of falling into a local optimum in searching the problem's space and providing consistent results. The GA is therefore a welcome addition to toolbox useful in forecasting stress in this important industry. 


\section{Endnotes}

1. Dimensionality reduction involves reducing the number of random variables under consideration for each observation in a data set and makes the data easier to work with. This can be accomplished either by using a function to map the data from a multi-dimensional space to a lower dimensional space or by feature selection.

2. Feature selection is a technique for identifying and selecting a subset of the relevant features associated with each observation in a data set. It is also known as variable selection, feature reduction, attribute selection or variable subset selection.

3. The genetic algorithm can search in parallel since it has several candidate solutions being examined at the same time. This allows a parallel search through the problem space and results in shorter computational times.

4. A disjunctive is a clause (a rule) in a logical statement that has a value of true or false and the clauses are separated by an "OR." Each rule is a conjunction of attribute-operator-value conditions. For example, the logical statement (CA/TA $<0.5$ AND CA/TLIAB $<=0.85$ THEN INSOLVENT) OR (CA/REV $<0.239$ AND EXP/SALES $<0.996$ AND TLIAB/TA $<0.603$ THEN INSOLVENT) has two disjunctives.

5. Data is normalized to scale data values when the magnitude of data values may skew the results or when the data value do not fall in a range required for computation in a statistical or artificial intelligence model. The neural network model used in this research requires that data be between -1 and 1 . The data used in this research was divided by the maximum data value.

\section{References}

Altman, E. "Financial Ratios, Discriminant Analysis and the Prediction of Corporate Bankruptcy." The Journal of Finance (1968): 589-609.

Altman, E. Corporate Financial Distress. A Complete Guide to Predicting, Avoiding, and Dealing with Bankruptcy. John Wiley \& Sons, Inc., New York, 1983.

Altman, E.I, Predicting Financial Distress of Companies: Revisiting the Z-Score and Zeta ${ }^{\circledR}$ Models. working paper at http://pages.stern nyu.edu/ ealtman/Zscores.pdf, 2000.

Altman, E., R. Haldeman, and P. Narayanan. "ZETAAnalysis: A New Model to Identify Bankruptcy Risk of Corporations.” Journal of Banking and Finance (1977): 29-54.

Anandarajan, M., P. Lee, and A. Anandarajan. "Bankruptcy Prediction of Financially Stressed Firms: An Examination of the Predictive Accuracy of Artificial Neural Networks." International Journal of Intelligent Systems in Accounting, Finance \& Management 10, (2001): 69-81.

Archer, N.P. and S. Wang. "Application of the Back Propagation Neural Networks Algorithm with Montonically Constraints for Two-Group Classification Problems.” Decision Sciences 24(1), (1993): 60-75.

Back, B., T. Laitinen, and K. Sere. “Neural Networks and Bankruptcy Prediction.” Paper presented at the 17th Annual Congress of the European Accounting Association, Venice, Italy. Abstract in Collected Abstracts of the 17th Annual Congress of the European Accounting Association, (1994): 116. 
Forecasting Air Carrier Financial Stress

Back, B., T. Laitinen, K. Sere, and M. van Wezel. "Choosing Bankruptcy Predictors Using Discriminant Analysis, Logit Analysis, and Genetic Algorithms.” Turke Centre for Computer Science, Technical Report No. 40, September, 1996.

Back, B., T. Laitinen, and K. Sere. "Neural Networks and Bankruptcy Prediction: Funds Flows, Accrual Ratios, and Accounting Data.” Advances in Accounting 14, (1996a): 23-37.

Back, B., T. Laitinen, J. Hekanaho, and K. Sere. "The Effect of Sample Size on Different Failure Prediction Methods.” Turku Centre for Computer Science. TUCS Technical Report No. 155, December, 1997.

Beaver, W. "Financial Ratios as Predictors of Failure.” Empirical Research in Accounting: Selected Studies, supplement to vol.5, Journal of Accounting Research, (1966): 71-111.

Bell, T.B., G.S. Ribar, and J. Verchio. "Neural Nets vs. Logistic Regression: A Comparison of Each Model's Ability to Predict Commercial Bank Failures.” Proceedings of the 1990 Deloitte Touche/ University of Kansas Symposium on Auditing Problems, (1990): 29-53.

Bhattacharyya, S. and P.C. Pendharkar. "Inductive, Evolutionary and Neural Computing Techniques for Discrimination: A Comparative Study.” Decision Sciences Journal 29 (4), (1998).

Boritz, J.E., D.B. Kennedy, and A de Miranda de al.buquerque. "Predicting Corporate Failure Using a Neural Network Approach.” Intelligent Systems in Accounting, Finance and Management 4, (1995): 95-111.

Brockett, P.L., W.W. Cooper, L.L. Golden, and U. Pitaktong. "A Neural Network Method for Obtaining an Early Warning of Insurer Insolvency.” The Journal of Risk and Insurance 61 (3), (1994): 402-424.

Chung, H.M. and K.Y. Tam. “A Comparative Analysis of Inductive-Learning Algorithms.” Intelligent Systems in Accounting, Finance and Management, March 1992.

Coats, P.K. and L.F. Fant. "Recognizing Financial Distress Patterns Using a Neural Network Tool.” Financial Management, ( 1993): 142-155.

Chow G., R. Gritta and E. Leung. “A New Approach to Forecasting Financial Distress in Air Transportation: The AIRSCORE Model.” Journal of the Transportation Research Forum 31 (2), (1991): 371-376.

Colin, A. "Genetic Algorithms for Financial Modeling.” G. Debocek ed. Trading on the Edge. John Wiley \& Sons, New York, 1994.

Courtis, J.K. “Modeling a Financial Ratio Categoric Framework.” Journal of Business Finance and Accounting 5 (4), (1978): 371-386.

Davalos, S., R. Gritta, and W. Wang. "Small U.S. Air Carrier Financial Condition: A Back Propagation Neural Network Approach to Forecasting Bankruptcy and Financial Stress.” Journal of the Transportation Research Forum published in Transportation Quarterly 56 (2), (2002): 35-46.

Davalos, S., R. D. Gritta, and D. Bright. "The Prediction of Stress and Failure in the U.S. Airline Industry using a Genetic Algorithm.” ATRS World Conference: Nagoya, Japan, May (2006): 2628 .

Deakin, E. “A Discriminant Analysis of Predictors of Business Failure.” Journal of Accounting Research, Spring (1972): 167-179. 
Debocek, Guido, J. Trading on the Edge. John Wiley \& Sons. A Wiley Finance edition, New York, 1994.

Dimitras, A.I., S.H. Zanakis, and C. Zopounidis. "A Survey of Business Failure with an Emphasis on Prediction Methods and Industrial Application.” European Journal of Operational Research 90, (1996): 487-513.

Etheridge, H.L. and R.S. Sriram. "A Neural Network Approach to Financial Distress Analysis.” Advances in Accounting Information Systems, (1996): 201-222.

Etheridge, Harlan L. and Ram S. Sriram. “A Comparison of the Relative Costs of Financial Distress Models: Artificial Neural Networks, Logit and Multivariate Discriminant Analysis." International Journal of Intelligent Systems in Accounting, Finance and Management, (1997): 235-248.

Fanning, K. and K.O. Cogger. "A Comparative Analysis of Artificial Neural Networks Using Financial Distress Prediction.” Intelligent Systems in Accounting, Finance and Management, December, 1994.

Feroz, E. and T. Kwon. "A Multilayered Perceptron (MLP) Approach to Prediction of the SEC's Investigation Targets.” IEEE Transactions on Neural Networks 7 (5), (1996): 1286-1290.

Fidelis, M.V., H.S. Lopes and A.A. Freitas. "Discovering Comprehensible Classification Rules with a Genetic Algorithm.” Proc. Congress on Evolutionary Computation - 2000 (CEC-2000), 805-810. La Jolla, CA, USA, July/2000. IEEE, 2000.

Fisher, R. A. "The Use of Multiple Measurements in Taxonomic Problems.” Annals of Eugenics 7, (1936): 179-188.

Galvao, H.K.H., V.M. Becerra, and M. Abou-Seada. "Variable Selection For Financial Distress Classification Using a Genetic Algorithm." 2002 Congress on Evolutionary Computation, May 1217, Honolulu, Hawaii, (2002): 2000-2005.

Gilbert, L.R., K. Menon, and K.B. Schwartz. "Predicting Bankruptcy for Firms in Financial Distress.” Journal of Business Finance and Accounting, Spring 1990.

Goldberg, D. Genetic Algorithms in Search, Optimization, and Machine Learning. Addison-Wesley, Reading, MA, 1989.

Goodfriend, Jason, R. Gritta, B. Adrangi, and S. Davalos. “Assessing the Financial Condition of the Major U.S. Passenger Airlines Over the 1993-2003 Period Using the P-Score and Z-Score Discriminant Models.” Credit and Financial Management Review, (2005).

Gritta R., S. Davalos, and G. Chow. "Gauging the Financial Condition of the Major U.S. Air Carriers.” Journal of Transportation Law, Logistics and Policy 71 (1), (2003): 116-122.

Grover, J. and A. Lavin. "Financial Ratios, Discriminant Analysis and the Prediction of Corporate Bankruptcy: A Service Industry Extension of Altman’s Z-Score Model of Bankruptcy Prediction.” Southern Finance Association Annual Meeting, November, 2001.

Hamer, M. "Failure Prediction: Sensitivity of Classification Accuracy to Alternative Statistical Method and Variable Sets.” Journal of Accounting and Public Policy 2 Winter, (1983): 289-307.

Hansen, J.V. and W.F. Messier. "Artificial Neural Networks: Foundations and Application to a Decision Problem.” Expert Systems with Applications, 1991. 
Forecasting Air Carrier Financial Stress

Hekanaho, J. “GA-Based Rule Enhancement in Concept Learning.” Proceedings of the 3rd International Conference on Knowledge Discovery and Data Mining. Newport Beach, CA. (1997): 183-186.

Hekanaho, J., B. Back, K. Sere, and T. Laitinen. “Analyzing Bankruptcy Data with Multiple Methods.” Proceedings of the 4th International Workshop on Multistrategy Learning (MSL'98). Brescia, Italy, June, 1998.

Holland, J. Adaption in Natural and Artificial Systems. University of Michigan Press: Ann Arbor, Michigan, 1997.

Hopwood, W., J.C. McKeown, and F.J. Mutchler. "A Reexamination of Auditor Versus Model Accuracy within the Context of the Going Concern Opinion Decision.” Contemporary Accounting Research 10 (2), (1994): 408-431.

Hornick, K., M. Stinchcombe, and H. While. "Multilayer Feedforward Networks are Universal Approximators.” Neural Networks 2, (1989): 359-366.

Klecka, W.R. Discriminant Analysis. Sage Publications, Beverly Hills, CA, 1980.

Koh, H.C. and L.N. Killough. "The Use of Multiple Discriminant Analysis in the Assessment of the Going-concern Status of an Audit Client.” Journal of Business Finance and Accounting, Spring 1990.

Lacher, R.C., P.K. Coats, S.C. Sharma, and L.F. Fant. "A Neural Network for Classifying the Financial Health of a Firm.” European Journal of Operational Research 85, (1995): 53-65.

Lensberg, T., A. Eilifsen, and T.E. McKee. "Bankruptcy Theory Development and Classification via Genetic Programming.” European Journal of Operational Research 169 (2), (2004): 677-697.

Lev, B. Financial Statement Analysis, A New Approach. Prentice-Hall, Englewood Cliffs, NJ, 1974.

Liang, T.P., J.S. Chandler, I. Han and J. Roan. “An Empirical Investigation of Some Data Effects on the Classification Accuracy of Probit, ID3, and Neural Networks." Contemporary Accounting Research, Fall 1992.

Mahfoud, S. and G. Mani. “Genetic Algorithms for Predicting Individual Stock Performance.” Proceedings of the Third International Conference on Artificial Intelligence Applications on Wall Street, Gaithersburg, Md.: Software Engineering Press, (1995): 174-181.

Markham, I.S. and C.T. Ragsdale. "Combining Neural Networks and Statistical Predictions to Solve Classification Problem in Discriminant Analysis.” Decision Sciences 26 (2), (1995): 229-242.

Messier, W.F. Jr and J.V. Hansen. "Inducing Rules for Expert System Development: An Example Using Default and Bankruptcy Data.” Management Science 34 (12), (1988): 1403-1415.

Michalski, R.S. “A Theory and Methodology of Inductive Learning.” Artificial Intelligence 20, (1983): 111-161.

Odom, M. and R. Sharda, “A Neural Network Model for Bankruptcy Prediction.” Proceedings of the International Joint Conference on Neural Networks, June (1990): II-163-II-168.

Ohlson, J. "Financial Ratios and the Probabilistic Prediction of Bankruptcy.” Journal of Accounting Research Spring, (1980): 109-131. 
O’Leary, D. E. “Using Neural Networks to Predict Corporate Failure.” International Journal of Intelligent Systems in Accounting, Finance \& Management 7 (3), (1998): 187-197.

Patuwo, E., M.Y. Hu, and M.S. Hung. "Two Group Classification Using Neural Networks.” Decision Sciences 24 (4), (1993): 825-845.

Platt, J.D. and M.B. Platt. "Development of a Class of Stable Predictive Variables: The Case of Bankruptcy Prediction.” Journal of Business Finance and Accounting 17 (1), (1990): 31-51.

Rutan, E. "Experiments with Optimal Stock Screens.” Proceedings of the 3rd International Conference on Artificial Intelligence Applications on Wall Street (1993): 269-273.

Salchenberger, L.M., E.M. Cinar, and N.A. Lash. "Neural Networks: A New Tool for Predicting Thrift Failures.” Decision Sciences 23 (4), (1992): 899-916.

Sexton, R.S., R.S. Sriram, and H. Etheridge. "Improving Decision Effectiveness of Artificial Neural Networks: A Modified Genetic Algorithm Approach.” Decision Sciences 34 (3), (2003): 421-442.

Sharda, R. “Neural Networks for the MS/OR Analyst: An Application Bibliography.” Interfaces 24 (2), (1994): 116-130.

Sharda R. and R.L. Wilson. "Neural Network Experiments in Business-Failure Forecasting: Predictive Performance Measurement Issues.” International Journal of Computational Intelligence and Organizations 1 (2), (1996): 107-117.

Shin, K. and I. Han. "A Genetic Algorithm Application in Bankruptcy Prediction Modeling.” Knowledge-Based Intelligent Information and Engineering Systems: 8th International Conference, KES 2004, Wellington, New Zealand, September 20-25, 2004, Proceedings, Part II Editors: Mircea Gh. Negoita, Robert J. Howlett, Lakhmi C. Jain, 2004.

Shin, Kyung-Shik and L. Lee. "A Genetic Algorithm Application in Bankruptcy Prediction Modeling.” Expert Systems with Applications 23 (3), ( 2002): 321-328.

Sikora, R., and M. J. Shaw. "A Double-Layered Learning Approach to Acquiring Rules for Classification: Integrating Genetic Algorithms with Similarity-Based Learning." ORSA Journal on Computing 6 (2), (1994): 174-187.

Taffler, R. and B. Houston. "How to Identify Failing Companies Before It Is Too Late.” Professional Administration, April (1980): 2-3.

Tam, K.Y. "Neural Network Models and the Prediction of Bank Bankruptcy." OMEGA 19 (5), (1991): 429-445.

Tam, K.Y. and M.Y. Kiang. "Managerial Applications of Neural Networks: The Case of Bank Failure Predictions.” Management Science 38 (7), (1992): 926-947.

Tan, P., M. Steinbach, and V. Kumar. Introduction to Data Mining. Pearson Education, Inc. Boston, MA, 2006.

U.S. Department of Transportation. Air Carrier Financial Statistics Quarterly. Washington, D.C., various issues.

Varetto, F. "Genetic Algorithms Applications in the Analysis of Insolvency Risk.” Journal of Banking and Finance 22, (1998): 1421-1439. 
Forecasting Air Carrier Financial Stress

Wilson, R.L. and R. Sharda. "Bankruptcy Prediction Using Neural Networks.” Decision Support Systems 11, (1994): 545 - 557.

Wilcox, J.W. “A Prediction of Business Failure Using Accounting Data.” Journal of Accounting Research 11, (1973).

Yoon, Y., G. Swales, and T.M. Margavio. "A Comparison of Discriminant Analysis versus Artificial Neural Networks.” Journal of Operations Research Society 44(1), (1993): 51-60.

Zavgren, C. "The Prediction of Corporate Failure: The State of the Art." Journal of Accounting Literature 1, (1983): 1-38.

Zhang, D. and L. Zhou. "Discovering Golden Nuggets: Data Mining in Financial Application.” IEEE Transactions on Systems, Man, and Cybernetics - Part C: Applications and Reviews 34 (4), (2004).

Zhang G., M.Y. Hu, B.E. Patuwo, and D.C. Indro. "Artificial Neural Networks in Bankruptcy Prediction: General Framework and Cross-Validation Analysis.” European Journal of Operational Research 116, (1999): 16-32.

Zmijewski, M. E. "Methodological Issues Related to the Estimation of Financial Distress Prediction Models.” Journal of Accounting Research 24 (Supplement), (1984): 59-82.

Sergio Davalos (PhD-University of Arizona) is an assistant professor in the Milgard School of Business at the University of Washington-Tacoma. His research interests include developing knowledge and information comprehension support through computer-based systems, application of machine learning techniques for financial problems, application of agent technology for organizational computation modeling, and use of biological mechanisms for addressing organizational computing needs. He has published in the Journal of the Transportation Research Forum, the Journal of Air Transport Management, Journal of Financial Management and Analysis, and the Credit and Financial Management Review.

Richard Gritta (PhD-University of Maryland) is a professor of finance and transportation at the R.B. Pamplin Jr. School of Business, University of Portland. This Fall, he is a visiting Senior Fulbright Specialist at the Toulouse School of Business in France teaching in the ESC's MBA Program in air transport management. His research interests include airline financial patterns, air carrier bankruptcy forecasting, and risk and return in air transportation. His papers have appeared in the Journal of the Transportation Research Forum, Journal of Air Transport Management, Transportation Journal, The Logistics and Transportation Review, Financial Analysts' Journal, Credit and Financial Management Review, and many others. He is currently Associate Editor-Air Transportation for the Journal of the Transportation Research Forum and has served as an advisor to U.S. Sen. Ron Wyden (D-Oregon: U.S. Senate Aviation Subcommittee) on airline matters.

Bahram Adrangi (PhD-University of Oregon) is a professor of economics at the R.B. Pamplin Jr. School of Business, University of Portland. His areas of research interest are transportation economics, financial economics, and international economics. His published papers have appeared in the Journal of Transport Economics and Policy, Transportation Journal, The Logistics and Transportation Review, Journal of Futures Market, Journal of Industrial Organization, Journal of Business Finance and Accounting, among others. 
Appendix One: Air Carriers Used in Study

\begin{tabular}{|l|}
\hline UNITED \\
\hline AIR WISCONSIN \\
\hline ALASKA \\
\hline ALOHA \\
\hline AMERICAN \\
\hline CONTINENTAL \\
\hline DELTA \\
\hline EASTERN \\
\hline BRANIFF \\
\hline TWA \\
\hline USAIR \\
\hline HAWAIIAN \\
\hline HORIZON \\
\hline MIDWAY \\
\hline MIDWEST \\
\hline NORTHWEST \\
\hline SOUTHWEST \\
\hline PAN AM \\
\hline WORLD \\
\hline
\end{tabular}

Appendix Two: Air Carrier Variables Used In Study

\begin{tabular}{|l|l|}
\hline Revenue (REV) & Current Assets (CA) \\
\hline Depreciation & Operating Equipment \\
\hline Expense (EXP) & Total Assets (TA) \\
\hline EBIT & Current Liabilities (CLIAB) \\
\hline Interest & Taxes \\
\hline Income Before Taxes & Total Non-Current Liabilities \\
\hline Income After Taxes & Total Deferred Credits \\
\hline Net Income (NETINC) & Total Liabilities (TLIAB) \\
\hline Cash (CASH) & Retained Earnings (REARN) \\
\hline Receivables & Equity (EQUITY) \\
\hline
\end{tabular}

